\title{
Avaliação das respostas fisiológicas de bezerros zebuínos puros e cruzados nascidos em clima subtropical ${ }^{1}$
}

\section{Andréa Roberto Bueno Ribeiro ${ }^{2}$, Maurício Mello de Alencar ${ }^{3}$, João Alberto Negrão ${ }^{4}$, Mateus José Rodrigues Paranhos da Costa ${ }^{5}$, Josiane Maria Cardoso Starling ${ }^{6}$}

1 Parte da tese de Doutorado da primeira autora, financiada pela FAPESP.

2 Universidade do Grande ABC - UniABC, Santo André - SP, CEP: 06080-511.

${ }^{3}$ Embrapa Pecuária Sudeste, São Carlos - SP. Bolsista do Cnpq.

${ }^{4}$ Faculdade de Zootecnia e Engenharia de Alimentos - FZEA/USP, Pirassununga - SP.

${ }^{5}$ Faculdade de Ciências Agrárias e Veterinárias - FCAVIUNESP, Jaboticabal - SP. Bolsista do CNPq.

${ }^{6}$ Curso de Medicina Veterinária da Universidade de Franca - UNIFRAN, Franca - SP.

RESUMO - Estudou-se a influência de fatores climáticos sobre as respostas físiológicas de bezerros, puros e cruzados, filhos de vacas da raça Nelore ou de alta mestiçagem de Nelore acasaladas com touros das raças Aberdeen Angus (AN), Simental (SN), Canchim (CN) e Nelore (NI e NR). Os bezerros AN, SN, CN e NI foram mantidos em sistema rotacionado intensivo, enquanto o grupo NR foi mantido em sistema extensivo. Os bezerros foram observados de forma direta desde o nascimento até a primeira mamada, medindo-se a latência para a primeira mamada (LM). Aproximadamente 24 horas após o parto, coletaram-se amostras de sangue do bezerro para as dosagens de proteína total (PT), glicose (Gli), triiodotironina $\left(\mathrm{T}_{3}\right)$, tiroxina $\left(\mathrm{T}_{4}\right)$, relação $\mathrm{T}_{4}: \mathrm{T}_{3}$, cortisol (Cort) e imunoglobulina $\mathrm{G}$ (IgGb), além das medidas de temperatura retal do bezerro (TR) e dos pesos de vacas e bezerros. Para análise dos efeitos de clima, foram tomadas no dia do nascimento as medidas de temperatura do ar (Temp), umidade do ar (UR) e precipitação (PRE). Os parâmetros fisiológicos foram estudados pelo método dos quadrados mínimos com modelos que incluíram os efeitos de ano e mês de nascimento, grupo e sexo do bezerro, categoria da vaca e hora do parto e das interações ano $\times$ grupo e ano $\times$ mês de nascimento, além das covariáveis peso do bezerro, PRE, Temp, UR e LM. Temp mostrou efeito significativo para as concentrações de $\mathrm{T}_{3}, \mathrm{~T}_{4}, \mathrm{~T}_{4}: \mathrm{T}_{3}$ e de Cort. Quanto maior Temp, menores as concentrações de $\mathrm{T}_{3}$ e de Cort e maiores as de $\mathrm{T}_{4}$ e de $\mathrm{T}_{4}: \mathrm{T}_{3}$. LM influenciou os níveis de Cort, PT e IgGb, de modo que, quanto maior LM, maior a concentração de Cort e menor as de IgGb e PT. Também houve efeito significativo de grupo do bezerro sobre PT, que foi maior nos bezerros NR que nos bezerros NI.

Palavras-chave: clima, comportamento, nascimento, parâmetros fisiológicos

\section{Evaluation of physiological responses of straightbred and crossbred Zebu calves born in a subtropical environment}

\begin{abstract}
The influence of environmental parameters on the physiological responses of purebred and crossbred Nellore calves born in a subtropical region was studied. All calves were born from high grade Nellore cows sired by Aberdeen Angus (AN), Simmental (SN), Canchim (CN) and Nellore (NI) bulls. These calves were raised under intensive management and another group of Nellore calves (NR) was raised under extensive management, similar to the typical brazilian system for beef production. Calves were observed from birth until the end of the first suckling, and the variable first suckling latency (LM) was estimated. Aapproximately 24 hours after birth, blood samples were collected from each calf to measure the plasma concentrations of total protein $(\mathrm{PT})$, glucose (Gli), triiodothyronin $\left(\mathrm{T}_{3}\right)$, thyroxin $\left(\mathrm{T}_{4}\right), \mathrm{T}_{3}: \mathrm{T}_{4}$ ratio, cortisol (Cort) and immunoglobulin- $\mathrm{G}(\mathrm{IgGb})$. At the same time, the calves' rectal temperature was taken and the cows and the calves were weighed Climatic data of temperature (Temp), relative humidity (UR) and rain precipitation (PRE) in the birth day were also recorded Physiological parameters were analyzed by least squares method using a model that included the effects of year and month of calving, group of calf, sex of calf, cow category, calving time, year $\times$ group and year $\times$ month of birth interactions and the covariables calf's weight, PRE, Temp, UR and LM. The effect of Temp was significant for the concentrations of $\mathrm{T}_{3}, \mathrm{~T}_{4}$ $\mathrm{T}_{4}: \mathrm{T}_{3}$ and Cort. The concentrations of $\mathrm{T}_{3}$ and Cort decreased and the levels of $\mathrm{T}_{4}$ and $\mathrm{T}_{4}: \mathrm{T}_{3}$ ratio increased as Temp increased Similarly, the concentration of Cort increased and the concentrations of IgGb and PT decreased as LM increased. PT level was significantly higher in NR calves than in NI ones.
\end{abstract}

Key Words: behavior, birth, physiological parameters, environment 


\section{Introdução}

Um dos índices de eficiência reprodutiva mais importantes e utilizados na pecuária de corte é representado pela razão entre o número de bezerros produzidos pelo número de matrizes prenhes na estação de monta (Godfrey et al., 1991). Entre os fatores que podem afetar este índice, destaca-se a morte de bezerros no período perinatal. O evento do parto representa uma situação estressante para o bezerro, que, para sobreviver, deve adaptar-se rapidamente ao novo ambiente. Essa adaptação inclui absorção de ar, mobilização de energia, mudanças nos padrões circulatórios, iniciação da função gastrintestinal e regulação da temperatura corporal (Cappel, 1996).

Bull et al. (1980) relataram que de 8 a $25 \%$ dos bezerros não sobrevivem por mais de cinco dias após o nascimento. Entre as maiores causas dessa mortalidade, destacam-se a hipotermia, como resultado da excessiva perda de calor, a hipoxia, a fome e outros fatores que inibem a produção de calor, além da desnutrição materna, da baixa habilidade materna, das infecções e das lesões (Mellor \& Stafford, 2004).

Nesse contexto, a dificuldade dos bezerros em adaptar às condições ambientais adversas, como frio, flutuações de temperatura, vento e alta precipitação, têm especial relevância (Diesch et al., 2004; Godfrey et al., 1991).

Dentro da zona de conforto térmico, Rowan (1992) relatou valores de temperaturas ambientes críticas inferiores para bezerros recém-nascidos que variavam entre 9 e $22^{\circ} \mathrm{C}$, os quais estão diretamente relacionados ao grupo genético e à adaptação dos bezerros às condições climáticas em que nasceram. Por exemplo, em condições de baixas temperaturas, Josey et al. (1993) verificaram maior taxa de mortalidade de bezerros com maior proporção de sangue Bos indicus e relataram que essas taxas foram ainda maiores com o aumento da precipitação pluviométrica. Godfrey et al. (1991) concluíram que bezerros Brahman não regularam sua temperatura corporal ao nascimento tão bem quanto os bezerros cruzados, apresentando maiores concentrações de glicose, triiodotironina, tiroxina e triglicerídeos nas primeiras horas após o parto e que a temperatura corporal desses animais continuou baixa mesmo quando colocados em ambientes mais quentes.

Grande parte do rebanho de corte nacional (aproximadamente $80 \%$ ) é constituída de bovinos zebuínos ou azebuados, observando-se, nos últimos anos, importante aumento do uso do cruzamento industrial, em que matrizes zebuínas são acasaladas com touros europeus (Elzo \& Borjas, 2004). Pouco se sabe sobre as respostas adaptativas, desses bezerros, tanto dos zebuínos quanto dos cruzados, às condições climáticas subtropicais do Brasil. Assim, realizou-se este trabalho com o objetivo de analisar os efeitos do clima nas respostas fisiológicas de bezerros zebuínos puros e cruzados nascidos na Região Sudeste do Brasil.

\section{Material e Métodos}

A pesquisa foi conduzida na Embrapa Pecuária Sudeste, em São Carlos, SP, Brasil, a $22^{\circ} 01^{\prime}$ de latitude sul e $47^{\circ} 53^{\prime}$ de longitude oeste. O clima da região é subtropical com inverno seco e verão quente/úmido, apresentando médias de temperatura de $16,3^{\circ} \mathrm{C}$ (julho) a $23^{\circ} \mathrm{C}$ (fevereiro) e média anual de precipitação pluviométrica de $1.502 \mathrm{~mm}$.

Durante dois anos de coleta de dados, foram observados os nascimentos de 185 bezerros ( 89 em 1998 e 96 em 1999). Os bezerros eram filhos de vacas da raça Nelore ou de alta mestiçagem de Nelore acasaladas com touros das raças Aberdeen Angus (grupo AN), Simental (grupo SN), Canchim (grupo CN) e Nelore (grupos NI e NR). Os grupos AN, SN, $\mathrm{CN}$ e NI foram mantidos em sistema rotacionado intensivo (5 UA/ha, pastagens adubadas de Brachiaria brizantha cv. Marandu nas águas, com suplementação no período seco do ano) e o grupo NR foi mantido em sistema extensivo (1UA/ha, pastagens de Brachiaria decumbens) sem suplementação alimentar. Apenas 146 bezerros, 68 no primeiro ano (16 NR, $12 \mathrm{NI}, 9 \mathrm{CN}, 14 \mathrm{AN}$, e $17 \mathrm{SN})$ e 78 no segundo ano (18 NR, $16 \mathrm{NI}, 18 \mathrm{CN}, 11 \mathrm{AN}$, e $15 \mathrm{SN})$, foram observados até o final da primeira mamada, visto que alguns partos ocorreram no início do anoitecer, quando as observações eram cessadas por falta de luminosidade.

Quinze dias antes da parição, as vacas foram retiradas de seus grupos e levadas para um piquete maternidade, onde permaneceram até o dia seguinte após o parto. Nesse local, eram realizadas as observações de forma direta e contínua do nascimento até o final da primeira mamada, medindo-se a latência para a primeira mamada (LM), em minutos.

Aproximadamente 24 horas após o parto, vaca e bezerro eram levados para o curral para a coleta de sangue, pesagem e medida da temperatura retal dos bezerros. A coleta de sangue foi feita via punção jugular. Logo após a coleta, o sangue foi centrifugado à $2300 x g$ por 20 minutos para separação do plasma, que foi acondicionado em vários tubos de ependorf de 1,5 mL. A quantificação de proteína total foi feita imediatamente após a coleta do plasma utilizando-se um refratômetro manual (Refratômetro "N", Atago Co., Ltd. Box 767, Del Mar, CA 92014). Em seguida, os tubos foram congelados a $-20^{\circ} \mathrm{C}$ para as futuras análises de glicose, triiodotironina $\left(\mathrm{T}_{3}\right)$, tiroxina $\left(\mathrm{T}_{4}\right)$, cortisol e imunoglobulina $\mathrm{G}(\mathrm{IgG})$. Todas as amostras foram analisadas em duplicatas, de modo que, quando o coeficiente de variação (CV) ultrapassava $15 \%$, a amostra era reanalisada. As dosagens de 
glicose foram feitas por método enzimático, utilizando-se kit comercial(LABORLAB S/A prod. Para lab. Estrada do Capão Bonito, 937 cep: 07263-010 - São Paulo), e as leituras, em fotocolorímetro com filtro com comprimento de onda de $505 \mathrm{~nm}$. As determinações dos níveis plasmáticos de $\mathrm{T}_{3}, \mathrm{~T}_{4}$ e cortisol foram feitas por método imunoenzimático (EIA), utilizando-se kit comercial (Kit DSL - Diagnostic Systems Laboratories, Inc. Corp. Headquaters, Webster, Texas 77598217.USA), e as leituras, em fotocolorímetro, utilizando-se filtro com comprimento de onda de $450 \mathrm{~nm}$. Os coeficientes de variação inter e intra-ensaios para as dosagens de cortisol ( $\mathrm{T}_{3}$ e $\mathrm{T}_{4}$ ) foram de 6,1 e 5,0\%; 7,0 e 6,0\% e 4,2 e 5,4\%, respectivamente. Em todas as dosagens, as amostras que ultrapassaram o ponto mais alto da curva foram diluídas ereanalisadas. A quantificação plasmática de Imunoglobulina-G das mães e dos bezerros foi feita pelo método de imunodifusão radial (Mancini, 1965), adaptado por Pauletti (1999). Os dados climáticos (temperatura do ar, umidade do ar e precipitação) foram fornecidos pela Estação Meteorológica da Embrapa Pecuária Sudeste.

As concentrações de proteína total (PT), triiodotironina $\left(\mathrm{T}_{3}\right)$ e tiroxina $\left(\mathrm{T}_{4}\right)$ e a relação $\mathrm{T}_{4}: \mathrm{T}_{3}$, cortisol (Cort), glicose (Gli) e imunoglobulina do bezerro (IgGb) foram estudadas por meio de análises de variância (método dos quadrados mínimos), utilizando-se o procedimento GLM (SAS, 2000). Foi utilizado um modelo estatístico que incluiu os efeitos fixos de ano (1998 e 1999) e mês de nascimento (março/abril e maio/ junho), grupo (AN, SN, CN, NI e NR) e sexo do bezerro, a categoria da vaca (primípara e plurípara), a hora do parto (6 às $8 ; 8$ às 10; 10 às 12; 12 às 14; 14 às 16; e 16 às 19 h), as interações ano $\mathrm{x}$ grupo e ano $\mathrm{x}$ mês de nascimento, além das covariáveis (efeito linear) peso do bezerro ao nascimento, precipitação pluviométrica, temperatura do ar, umidade do ar e latência para mamar (LM). Para a análise de variância da temperatura retal dos bezerros (TR), o modelo foi idêntico, mas sem os efeitos de ano de nascimento do bezerro e de suas interações, pois a TR só foi coletada no segundo ano (1999).

Para todas as características, foi testada primeiramente a existência de interação da covariável peso do bezerro ao nascimento e $\times$ efeito de grupo do bezerro. Como a interação foi não-significativa, manteve-se a covariável peso do bezerro no modelo sem aninhá-la dentro de grupo.

\section{Resultados e Discussão}

Os resumos das análises de variância dos parâmetros fisiológicos estudados são apresentados nas Tabelas 1 (concentrações de $\mathrm{T}_{3}, \mathrm{~T}_{4}$ e relação $\mathrm{T}_{4}: \mathrm{T}_{3}$ ) e 2 (concentrações de cortisol, glicose, imunoglobulina-G, proteína total e temperatura retal).
Houve efeito $(\mathrm{P}<0,01$ e $\mathrm{P}<0,05)$ de ano e da interação ano $\times$ mês para $T_{4}, T_{4}: T_{3}$ e IgGb e de temperatura do ar para $\mathrm{T}_{3}, \mathrm{~T}_{4}, \mathrm{~T}_{4}: \mathrm{T}_{3}$ e cortisol. Na Tabela 3 são apresentados os valores máximos e mínimos de temperatura do ar, umidade relativa e precipitação pluviométrica coletados no período experimental. Os coeficientes de regressão indicaram que, quanto maior a temperatura do ar, maior a concentração de $\mathrm{T}_{4}\left(\mathrm{~b}=0,54 \mathrm{ug} / \mathrm{dL} /{ }^{\circ} \mathrm{C}\right)$ e a relação $\mathrm{T}_{4}: \mathrm{T}_{3}\left(\mathrm{~b}=1,88 \mathrm{ng} / \mathrm{dL} /{ }^{\circ} \mathrm{C}\right)$ e menor a concentração de cortisol $\left(\mathrm{b}=-1,079 \mathrm{ug} / \mathrm{dL} /{ }^{\circ} \mathrm{C}\right) \mathrm{e}$ de $\mathrm{T}_{3}\left(\mathrm{~b}=-10,12 \mathrm{ng} / \mathrm{dL} /{ }^{\circ} \mathrm{C}\right)$.

Entre as demais fontes de variação consideradas (grupo do bezerro, sexo, categoria da vaca, peso do bezerro, latência para a primeira mamada e interação grupo x sexo), também apresentaram efeitos (Tabela 2) o grupo do bezerro para PT $(\mathrm{P}<0,07)$ e a latência para a primeira mamada para Cort $(\mathrm{P}<0,05)$, $\mathrm{PT}(\mathrm{P}<0,01)$ e $\operatorname{IgGb}(\mathrm{P}<0,07)$, destacando-se as seguintes tendências: quanto maior LM menor as concentrações de $\operatorname{IgGb}(b=-0,0394 \mathrm{mg} / \mathrm{mL} / \mathrm{min})$ e de PT ( $b=-2,88 \mathrm{mg} / \mathrm{mL} / \mathrm{min}$ ) e maior a concentração de cortisol $(b=0,1026 \mathrm{ug} / \mathrm{dL} / \mathrm{min})$.

Independentemente do grupo genético do bezerro, as médias gerais estimadas foram de $39,24 \pm 0,70^{\circ} \mathrm{C}$ para TR e de $20,89 \pm 0,89 \mathrm{ug} / \mathrm{dL}, 136,25 \pm 3,11 \mathrm{mg} / \mathrm{dL}, 24,84 \pm$ $0,44 \mathrm{mg} / \mathrm{mL}, 633,15 \pm 12,29 \mathrm{ng} / \mathrm{dL}, 22,90 \pm 0,73 \mathrm{ug} / \mathrm{dL}$ e $39,64 \pm 1,70 \mathrm{ng} / \mathrm{dL}$ e 7,88 $\pm 0,08 \%$ para as concentrações plasmáticas de cortisol, glicose, imunoglobulina-G, $\mathrm{T}_{3}$, $\mathrm{T}_{4}, \mathrm{~T}_{4}: \mathrm{T}_{3}$ e proteína total, respectivamente.

Não foram encontrados efeitos $(\mathrm{P}>0,07)$ das fontes de variação incluídas no modelo sobre a TR, que apresentou média geral de $39,24 \pm 0,70^{\circ} \mathrm{C}$.

Os efeitos $(\mathrm{P}<0,05)$ relacionados ao ano, ao mês e à interação ano $\times$ mês de nascimento (Tabelas 1 e 2) podem estar relacionados ao fato de as vacas utilizadas no primeiro e segundo anos não terem sido exatamente as mesmas. Da mesma forma, foram utilizados diferentes touros nos dois anos. Além disso, apesar de terem sido incluídas fontes de variações ambientais no modelo, outros fatores não controlados, como radiação solar, vento, ocorrência de temporais, entre outros, poderiam influenciar essas diferentes respostas em determinado mês e ano.

Apesar dos baixos coeficientes de determinação das regressões, os resultados mostraram que quanto maior a temperatura do ar menores as concentrações de $\mathrm{T}_{3}$ e cortisol e maiores as de $T_{4}$ e a relação $T_{4}: T_{3}$ (Figura 1). Ao nascimento, os bezerros necessitam adaptar-se rapidamente ao novo ambiente. Essa adaptação inclui mobilização de energia, mudanças nos padrões circulatórios e regulação da temperatura corporal (Cappel, 1996). Uma das principais funções dos hormônios tireoidianos está relacionada à regulação da temperatura corporal, de modo que, em bezerros 
Tabela 1 - Resultado das análises de variância das concentrações plasmáticas de triiodotironina $\left(T_{3}\right)$ e tiroxina $\left(T_{4}\right)$ e da relação $T_{4}: T_{3}$ dos bezerros aproximadamente 24 horas após o nascimento

Table 1 - Analyses of variance for the plasmatic concentrations of triiodothyronin $\left(T_{3}\right)$, thyroxin $\left(T_{4}\right)$ and $T_{3}: T_{4}$ ratio of calves approximately 24 hours after birth

\begin{tabular}{|c|c|c|c|c|}
\hline \multirow[t]{2}{*}{$\begin{array}{l}\text { Fonte de variação } \\
\text { Source of variation }\end{array}$} & \multirow[t]{2}{*}{$\begin{array}{l}\text { GL } \\
D F\end{array}$} & \multicolumn{3}{|c|}{$\begin{array}{c}\text { Quadrado médio } \\
\text { Mean square }\end{array}$} \\
\hline & & $\mathrm{T}_{3}$ & $\mathrm{~T}_{4}$ & $\mathrm{~T}_{4}: \mathrm{T}_{3}$ \\
\hline Mês de nasc. (Mn) (Birth month - Mn) & 1 & 5618,00 & 17,12 & 2,02 \\
\hline Ano $\mathrm{x}$ Mn (Year $x \mathrm{Mn})$ & 1 & 6440,06 & $407,49^{* *}$ & $1552,71^{*}$ \\
\hline Grupo do bezerro (Si) (Calf group - Si) & 4 & 12054,08 & 82,82 & 377,68 \\
\hline $\mathrm{Si} \times \mathrm{Se}$ & 4 & 34143,92 & 17,06 & 37,74 \\
\hline Categoria da vaca (Cow category) & 1 & 4097,49 & 2,59 & 305,95 \\
\hline Hora do parto (Birth time) & 5 & 24003,66 & 73,03 & 154,75 \\
\hline Peso do bezerro (Calf weight) & 1 & 1023,81 & 19,06 & 336,82 \\
\hline Precipitação (Rainfall) & 1 & 6819,19 & 0,00 & 190,97 \\
\hline Temperatura (Temperature) & 1 & $89232,42^{*}$ & $215,61^{*}$ & $2483,68^{* *}$ \\
\hline $\mathrm{R}^{2}(\%)$ & & 30,75 & 47,84 & 54,95 \\
\hline
\end{tabular}

$1 \mathrm{GL}$ para T3, T4 e T4:T3.

1 DF for T3, T4 and T4:T3.

${ }^{*} \mathrm{P}<0,05 ;{ }^{* \star} \mathrm{P}<0,01$.

Tabela 2 - Resultado das análises de variância das concentrações plasmáticas de cortisol (Cort), glicose (Gli) e imunoglobulina no bezerro (IgGb), da porcentagem de proteína total (PT) e da temperatura retal (TR) dos bezerros aproximadamente 24 horas após o nascimento

Table 2 - Analyses of variance for the plasmatic concentrations of cortisol (Cort), glucose (Gli) and immunoglobulin-G of the calf (IgGb), total protein (PT) and rectal temperature (TR) of calves approximately 24 hours after birth

\begin{tabular}{|c|c|c|c|c|c|c|}
\hline \multirow[t]{2}{*}{$\begin{array}{l}\text { Fonte de variação } \\
\text { Source of variation }\end{array}$} & \multirow[t]{2}{*}{$\begin{array}{l}\text { GL } \\
D F\end{array}$} & \multicolumn{5}{|c|}{$\begin{array}{c}\text { Quadrado médio } \\
\text { Mean square }\end{array}$} \\
\hline & & Cort & Gli & $\operatorname{IgGb}$ & $\mathrm{PT}$ & TR \\
\hline Ano de nascimento (Birth year) & 1 & 44,76 & 649,31 & $398,66^{* *}$ & 2,05 & - \\
\hline Mês de nascimento (Birth month - Mn) & 1 & 3,07 & 721,61 & 1,78 & 1,65 & 0,42 \\
\hline Ano x Mês (Year x Mn) & 1 & 26,04 & 21,03 & $389,59^{* *}$ & 3,28 & - \\
\hline Grupo do bezerro $(\mathrm{Si})$ (Calf group - Si) & 4 & 73,65 & 1652,51 & 31,06 & $2,38^{+}$ & 0,36 \\
\hline Ano $x \mathrm{Si}$ (Year $x \mathrm{Si})$ & 4 & 33,91 & 192,24 & 35,05 & 1,21 & - \\
\hline $\operatorname{Sexo}(\mathrm{Se})(\mathrm{Sex}-\mathrm{Se})$ & 1 & 43,01 & 1561,31 & 7,05 & 0,11 & 0,08 \\
\hline $\mathrm{Si} \times \mathrm{Se}$ & 4 & 84,68 & 2036,59 & 10,90 & 0,38 & 0,33 \\
\hline Categoria da vaca (Cow category) & 1 & 43,73 & 896,91 & 13,81 & 0,10 & 0,32 \\
\hline Hora do parto (Birth time) & 5 & 43,62 & 456,99 & 10,27 & 0,41 & 0,26 \\
\hline Peso do bezerro (Calf weight) & 1 & 167,75 & 804,92 & 0,06 & 0,00 & 0,12 \\
\hline Precipitação (Rainfall) & 1 & 289,42 & 4,32 & 1,91 & 0,21 & 0,21 \\
\hline Temperatura (Temperature) & 1 & $994,04^{* *}$ & 571,72 & 13,89 & 0,67 & 0,46 \\
\hline Umidade relativa (Relative humidity) & 1 & 106,68 & 830,94 & 56,11 & 2,93 & 0,21 \\
\hline Latência $\mathrm{p} /$ mamar (Suckling latency) & 1 & $568,69^{*}$ & 3387,41 & $82,13^{+}$ & $8,80^{* *}$ & 1,17 \\
\hline Resíduo $^{1}$ (Residual) & 100 & 102,03 & 1161,60 & 23,94 & 1,06 & 0,41 \\
\hline CV $(\%)$ & & 47,95 & 25,38 & 19,09 & 11,31 & 1,61 \\
\hline $\mathrm{R}^{2}(\%)$ & & 35,22 & 23,67 & 38,20 & 25,44 & 27,40 \\
\hline
\end{tabular}

1 GL igual a 93, 97, 103 e 48 para Gli, IgGb, PT e TR, respectivamente.

1 DF equal to $93,97,103$ and 48 for Gli, Ig Gb, PT and TR, respectively.

$+\mathrm{P}<0,07 ;{ }^{*} \mathrm{P}<0,05 ;{ }^{* *} \mathrm{P}<0,01$.

recém-nascidos, este processo é vinculado à termogênese do tecido adiposo marrom, processo dependente da ação do $\mathrm{T}_{3}$. Assim, são esperados aumentos nas concentrações dos hormônios tireoidianos logo após o nascimento (Chen et al., 1996), os quais serão mais pronunciados quanto maior o estresse pelo frio (Sampelayo, 2000), ocorrendo, de forma contrária, a redução da atividade da glândula tireóide em temperaturas elevadas (Yousef et al., 1967).

Assim, as variações de $T_{3}$ e $T_{4}$, com o aumento da temperatura do ar, a diminuição na concentração de $T_{3}$ 
A

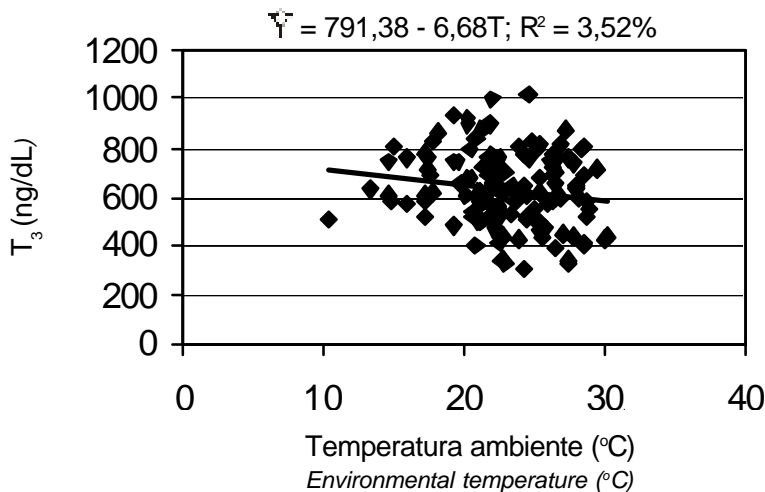

C

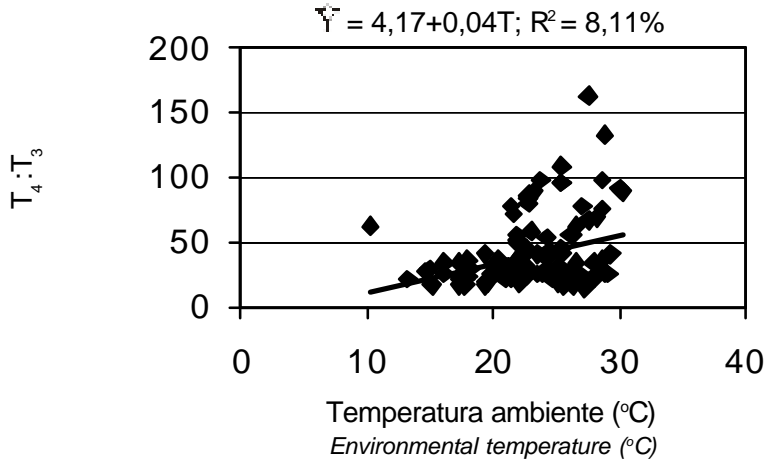

B

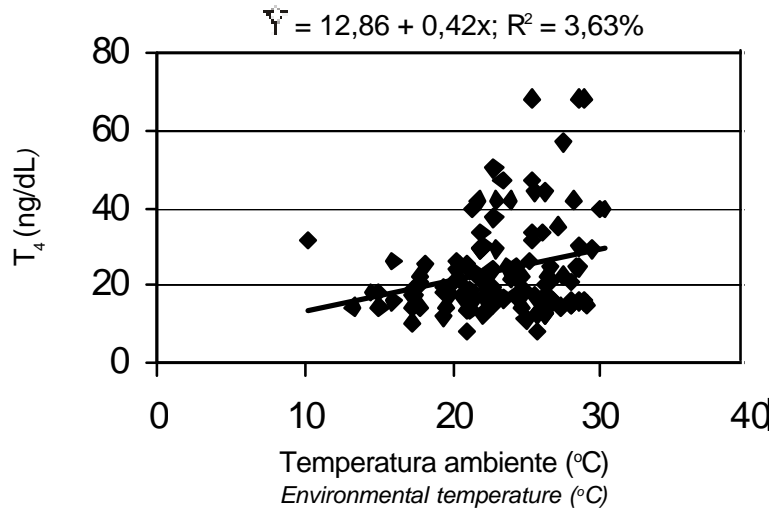

D

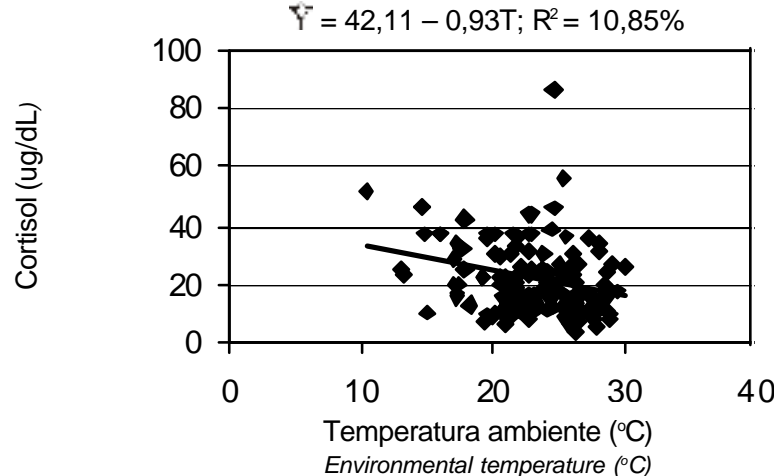

Figura 1 - Estimativas da concentração plasmática de triiodotironina $\left(T_{3}\right)(a)$, tiroxina $\left(T_{4}\right)(b)$, cortisol (c) e da relação $T_{4}: T_{3}(d)$ nos bezerros, aproximadamente 24 horas após o nascimento, de acordo com a temperatura ambiente na hora do nascimento ( $T$ ).

Figure 1 - Estimates of plasmatic concentrations of triiodothyronine $\left(T_{3}\right)(a)$, tiroxine $\left(T_{4}\right)(b)$, cortisol $(c)$, and $T_{4}: T_{3}$ ratio (d) of calves approximately 24 hours after birth, as function of the environmental temperature of the day of birth.

(Figura 1a) e o aumento da relação $\mathrm{T}_{4}: \mathrm{T}_{3}$ (Figura 1c), seguem o padrão esperado, visto que essa situação requer menor ativação de mecanismos termogênicos, diminuindo a atividade tireoidiana e a necessidade da conversão de $\mathrm{T}_{4}$ em $\mathrm{T}_{3}$.

Contudo, o aumento das concentrações de $\mathrm{T}_{4}$ com a elevação da temperatura do ar (Figura 1b) pode ser, na realidade, resultado de uma combinação de efeitos indiretos, como os descritos a seguir: o aumento das concentrações dos hormônios tireoidianos observado normalmente após o parto, em decorrência da necessidade de termorregulação dos bezerros ao nascimento, é muito mais rápido para o $\mathrm{T}_{3}$ que para o $\mathrm{T}_{4}$ (Nathanielsz \& Fisher, 1979); assim, 24 horas após o parto, o nível de $\mathrm{T}_{3}$ estaria baixo por já ter sido metabolizado, uma vez que sua meia-vida no soro sangüíneo é de aproximadamente 1 (um) dia e o nível de $\mathrm{T}_{4}$ ainda estaria aumentando, de modo que sua meia-vida no soro seria de, aproximadamente, sete dias (Green 1987); no caso de esses hormônios não serem necessários (em temperaturas mais altas), $T_{3}$ não continuaria a ser formado por meio da deiodinação do $\mathrm{T}_{4}$ e apresentaria níveis baixos ou estabilizados, mas os níveis de $\mathrm{T}_{4}$ ainda estariam altos. De forma complementar, essa variação também poderia ser decorrente da estimulação de mecanismos de feed-back
Tabela 3 - Valores máximos e mínimos de temperatura do ar (Temp, ${ }^{\circ} \mathrm{C}$ ), umidade relativa (UR, \%) e precipitação pluviométrica (PRE, mm) observados no período experimental dos anos de 1998 e 1999

Table 3 - Maximum and minimum values of air temperature $\left(T e m p,{ }^{\circ} \mathrm{C}\right)$, relative humidity (UR, \%) and rain precipitation (PRE, $\mathrm{mm}$ ) observed during the experimental period in years 1998 and 1999

\begin{tabular}{lcccc}
\hline & & Temp & UR & PRE \\
\hline Máximo & 1998 & 29,4 & 98,0 & 28,4 \\
Maximum & 1999 & 31,0 & 99,0 & 39,6 \\
Mínimo & 1998 & 14,6 & 40,0 & 0,0 \\
Minimum & 1999 & 10,3 & 30,0 & 0,0 \\
\hline
\end{tabular}

positivo desencadeados pelo baixo nível de $\mathrm{T}_{3}$, que levaria a tireóide a secretar mais $\mathrm{T}_{3}$ e $\mathrm{T}_{4}$, sendo a concentração de $\mathrm{T}_{4}$ bem maior que a de $\mathrm{T}_{3}$ (Anderson et al., 1988). Resultados semelhantes foram citados por Collin et al. (2002) e Herpin et al. (2002).

As menores concentrações de cortisol observadas com o aumento da temperatura do ar (Figura 1d) estão de acordo com os resultados relatados por Stanko et al. (1991), os quais, estudando bezerros da raça Brahman, encontraram níveis mais baixos de cortisol em condições de temperatura ambiente mais elevada e níveis mais altos em tempe- 
raturas baixas. Isso pode ser explicado pela melhor adaptação de zebuínos ao calor, sendo esperado que os bezerros deste grupo genético (puros e cruzados) estariam mais susceptíveis ao estresse em condições de baixa temperatura, resultando em maior secreção de cortisol.

Foi observado efeito de grupo do bezerro apenas para os níveis de proteína total (PT), com menores porcentagens $(\mathrm{P}<0,05)$ nos bezerros do grupo $\mathrm{NI}(7,67 \pm 0,23 \%)$ e maiores nos do grupo NR $(8,29 \pm 0,23 \%)$. Destaca-se o fato, apesarde não-significativo, de que os bezerros do grupo NI, nos quais as latências para mamar foram maiores que nos bezerros do grupo NR (74,79 \pm 4,98 x 65,87 \pm 5,87 min.), também houve menor concentração de $\operatorname{IgGb}(24,86 \pm 1,12$ x 26,41 $\pm 1,12 \mathrm{mg} / \mathrm{mL})$ e maior de glicose $(145,66 \pm 8,16 \mathrm{x}$ $130,60 \pm 7,91 \mathrm{mg} / \mathrm{dL})$. Assim, embora não-significativas, essas diferenças corroboram o efeito de PT encontrado para os dois grupos, visto que, como os bezerros NR mamaram mais rapidamente após o nascimento, apresentaram probabilidade de melhor aquisição de $\operatorname{IgGb}$, o que resultou em maior concentração de proteínas totais plasmáticas, altamente correlacionada à IgG após a ingestão do colostro no primeiro dia pós-nascimento (Machado Neto, 1985).

Não foram encontrados estudos na literatura comparando bezerros ao nascimento em sistemas intensivos e extensivos. Lay et al. (1997) relataram que vacas Brahman submetidas ao estresse de manejo durante a gestação produziram bezerros com maiores pesos relativos da hipófise e do coração, sugerindo que o estresse pré-natal influenciou a função do eixo HPA fetal, que controla diversas funções no organismo, entre elas, o crescimento e a maturação dos tecidos. Nathanielsz \& Fisher (1979) também relataram que a infusão de doses de cortisol em ovelhas gestantes resultou em antecipação da maturação dos diversos sistemas corporais e da data do nascimento. De acordo com esses estudos, as diferenças encontradas entre NR e NI podem estar relacionadas ao estresse da transferência das vacas do sistema extensivo (localizado na região mais afastada e de menor movimentação da fazenda) para o piquete maternidade, juntamente com as vacas dos sistemas intensivos, aproximadamente 15 dias antes da data do parto. Como hipótese, é razoável supor-se que o aumento na atividade do eixo HPA, decorrente do estresse pré-parto, teria acelerado a maturidade fisiológica dos bezerros NR, aumentando seu vigor ao nascimento, quando comparados aos NI. Entretanto, essa expectativa necessita ser avaliada com desenho experimental específico.

Os resultados das análises de regressão mostraram que, quanto maior a latência para a primeira mamada, maior a concentração de cortisol, menor a de $\operatorname{IgGb}$ e menor a de proteína total no bezerro (Figuras $2 \mathrm{a}, \mathrm{b}$ e c).

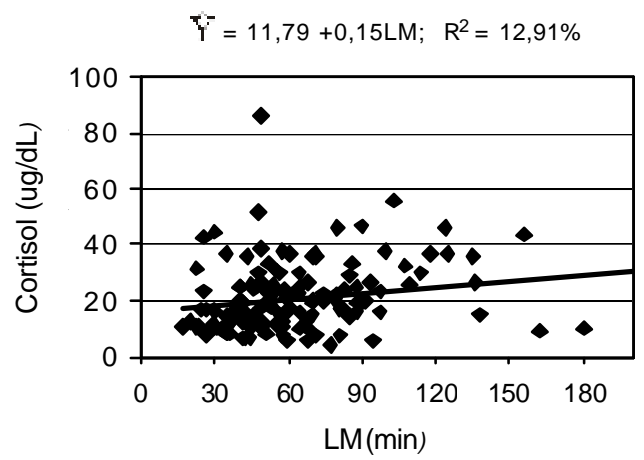

B

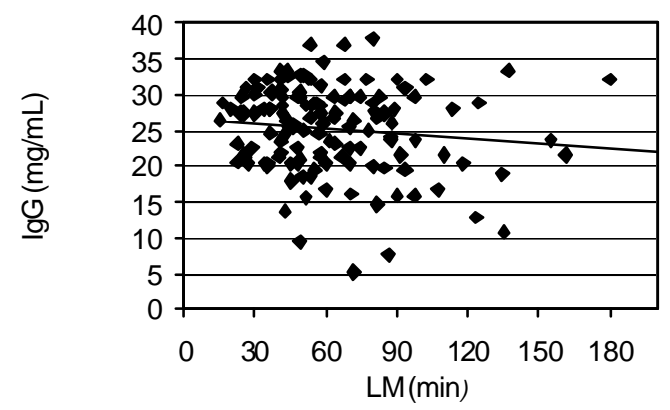

$\bar{Y}=8,54-0,09 L M ; R^{2}=5,89 \%$

C

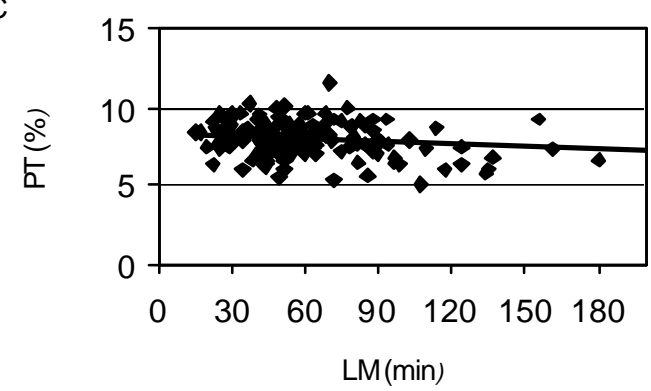

Figura 2 - Efeitos do período de latência para a primeira mamada (LM) sobre as estimativas das concentração plasmática de cortisol (a), imunoglobulina - G (IgGb) (b) e proteína total (PT) (c) nos bezerros aproximadamente 24 horas após o nascimento.

Figure 2 - Estimates of plasmatic concentrations of cortisol (a), immunoglobulin-G (IgGb) (b), and total protein (PT) (c) of calves approximately 24 hours after birth, as function of the first suckling latency (LM). 
Os bovinos fazem parte do grupo de espécies cuja transferência de imunoglobulinas durante a gestação é nula, devendo ocorrer por meio da ingestão do colostro após o nascimento. A aquisição de imunoglobulinas pelo bezerro é influenciada principalmente pela concentração de imunoglobulinas no colostro materno e pelo tempo entre o nascimento e a ingestão do colostro (Pauletti, 1999). Assim, a menor concentração plasmática de IgGb observada neste trabalho para os bezerros, em resposta ao aumento da latência para a primeira mamada (Figura 2b), era esperada (Rajala \& Castren, 1995; Pires et al., 1993).

Da mesma forma, as concentrações de proteína total diminuíram com o aumento da latência para a primeira mamada (Figura 2c). Estudos prévios comprovaram que a correlação entre as concentrações de proteína total plasmática e de imunoglobulinas em bezerros é baixa antes da ingestão do primeiro colostro, aumentando significativamente após a ingestão (Machado Neto, 1985) e mantendo-se alta (em torno de 0,8 ) nos primeiros dias de vida, (Nocek et al., 1984). Neste estudo também foi encontrada correlação significativa $(0,67)$ entre as concentrações de IgG e de proteína total 24 horas após o nascimento.

É importante ressaltar que, ainda que se tenha encontrado relação entre LM e as concentrações de PT e IgGb, independentemente do grupo do bezerro, o tempo entre o nascimento e a primeira mamada do bezerro $(59,47 \pm 26,27$ minutos) pode ser considerado adequado, não sendo esperado efeito importante na aquisição de imunidade passiva.

O aumento das concentrações de cortisol com a maior latência para mamar (Figura 2a) também está de acordo com os resultados relatados na literatura. Stanko et al. (1991) demonstraram que bezerros separados das mães 30 minutos após o nascimento demoravam maior tempo para mamar o primeiro colostro e apresentavam maiores concentrações de cortisol.

\section{Conclusões}

Em região subtropical, mesmo durante as estações de verão e outono, independentemente do grupo genético do bezerro, maior atenção deve ser dada aos bezerros nascidos em dias com temperatura mais baixa, pois, nessas condições, apresentam maior dificuldade de adaptação e regulação da temperatura corporal, evidenciada pelo padrão dos hormônios tireoidianos e cortisol após o nascimento.

Bezerros que demoram mais tempo para mamar após o nascimento apresentam maior estresse, com mais altos níveis de cortisol plasmático e menor aquisição de anticorpos.

\section{Literatura Citada}

ANDERSON, R.R.; NIXON, D.A.; AKASHA, M.A. Total and free thyroxine and triiodotironine in blood serum mammals. Comparative Biochemistry and Physiology, v. 89 A, n. 3 , p.401-405.

AZZAM, S.M.; KINDER, J.E.; NIELSEN, M.K. et al. Environmental effects on neonatal mortality of beef calves Journal of Animal Science, v.71, n.2, p.282-290, 1993.

BULL, R.C.; SASSER, R.G.; OLSON, D. et al. Calf death losses and reproductive failure as result of maternal protein deficiency. In: ANNUAL SCIENCE SEMINAR OF THE CALIFORNIA VETERINARY MEDICAL ASSOCIATION, 92., 1980, Davis. Proceedings... Davis: California Veterinary Medical Association, 1980. p.320.

CAPPEL, T. An evaluation of dystocia and the endocrine response to stress in the primiparous heifer and calf Lincoln: University of Nebraska, 1996. 85p. Thesis (Master in Animal Science) - University of Nebraska, 1996.

CHEN, L.; MAO, X.Z.; ZHU, Z.K. et al. Some characteristics of nutrition metabolism and hormone control during the first 24 hours in neonatal calves. Nutrition Hospital, v.11, n.1, p.43-46, 1996.

COLLIN, A.; VAZ, M.; DIVIDICH, J.L. Effects of high temperature on body temperature and hormonal adjustments in piglets. Reproduction Nutrition Development, v.42, n.1, p.4553, 2002

CORREA, E.S.; FILHO, K.E.; ALVES, R.G.O. et al. Desempenho reprodutivo em um sistema de produção de bovinos de corte. Campo Grande: EMBRAPA - CNPGC, 2001. (Boletim de Pesquisa, 13)

DIESCH, D.J.; MELLOR, K.J.; STAFFORD, R.N. The physiological and physical status of single calves at birth in a dairy herd in New Zealand. New Zealand Veterinary Journal, v.52, n.5, p. $250-255,2004$.

EDWARDS, S.A. Factors affecting the time to first suckling in dairy calves. Animal Prodution, v.34, n.2, p.339-346, 1982.

ELZO, M.A.; BORJAS, A.D.R. Perspectivas da avaliação genética multirracial em bovinos no Brasil. Ciência Animal Brasileira, v.5, n.1, p.171-185, 2004

GODFREY, R.W.; SMITH, S.D.; GUTHRIE M.J. et al. Physiological responses of newborn Bos indicus and Bos indicus x Bos taurus calves after exposure to cold. Journal of Animal Science, v.69, n.1, p.258-264, 1991

GREEN, W.L. Physiology of the thyroid gland and its hormones. In: GREEN, W.L. (Ed.) The thyroid. New York: Elsevier, 1987. p.1-46.

HERPIN, P.; DAMON, M.; DIVIDICH, J.L. Development of thermoregulation and neonatal survival in pigs. Livestock Production Science, v.78, n.1, p.25-45, 2002

JOSEY, M.F.; CUNDIFF, L.V.; KOCH, R.M. et al. Mortality and cold tolerance of calves with different ratios of Bos indicus to Bos taurus inheritance. Beef Research, v.4, p.52-54, 1993.

LAY JR., D.C.; RANDEL, R.D.; FRIEND, T.H. et al. Effects of prenatal stress on the fetal calf. Domestic Animal Endocrinology, v.14, n.2, p.73-80, 1997.

MACHADO NETO, R. Comportamento imunológico de bezerros da raça holandesa submetidos à diferentes regimes de aleitamento. Piracicaba: Escola Superior de Agricultura Luiz de Queiroz, 1985. 115p. Tese (Livre docência) - Escola Superior de Agricultura Luiz de Queiroz, 1985.

MANCINI, G.; CARBONARA, A.O.; HERMANS, J.F. Immunochemical quantitation of antigens by single radial immunodiffusion. Immunochemistry, v.2, n.3, p.253-254, 1965.

MELLOR D.J.; STAFFORD, K.J. Animal welfare implications of neonatal mortality and morbidity in farm animals. Veterinary Journal, v.168, n.2, p.118-133, 2004. 
NATHANIELSZ, P.W.; FISHER, D.A. Thyroid function in the prenatal period. Animal Reprodution Science, v.2, n.1, p.57-62, 1979.

NOCEK, J.E.; BRAUND, D.G.; WARNER, R.G. Influence of neonatal colostrum administration, immunoglobulin, and continued feeding of colostrum on calf gain, health and serum protein. Journal of Dairy Science, v.67, n.2, p.319-333, 1984.

PAULETTI, P. Efeito de diferentes níveis de imunoglobulinas adquiridas do colostro sobre a flutuação de proteínas séricas e desempenho de bezerras da raça holandesa. Piracicaba: Escola Superior de Agricultura Luiz de Queiroz, 1999. 103p. Tese (Mestrado em Agronomia) - Escola Superior de Agricultura Luiz de Queiroz, 1999.

PIRES, M.F.A.; CAMPOS, O.F.; CHARLES, T.N.P.C. et al. Alguns fatores que afetam o nível de imunoglobulinas no soro de bezerros de rebanhos leiteiros. Revista da Sociedade Brasileira de Zootecnia, v.22, n.6, p.985-992, 1993.

RAJALA, P.; CASTRÉN, H. Serum immunoglobulin concentrations and heath of dairy calves in two management systems from birth to 12 weeks of age. Journal of Dairy Science, v.78, n.12, p.2737-2744, 1995.

ROWAN, T.G. Thermorregulation in neonatal ruminants. In: VARLEY, M.A.; WILLIAMS, P.E.V.; LAWRENCE, T.L.J. (Eds.) Neonatal survival and growth. Edinburgh: British Society of Animal Production, 1992. p.13-24. (Occasional Publication, 15)
STATISTICAL ANALYSES SYSTEMS - SAS. User's guide. Version 8.2. Cary: 2000

SAMPELAYO, S.M.R.; PIETRO, L.; LUPIANI, M.J. et al. Physiological responses of pre-ruminant kid gotas and lambs to different environmental temperatures. Journal of Physiology Biochemistry, v.56, n.3, p.223-230, 2000.

STANKO, R.L.; GUTHRIE, M.J.; RANDEL, R.D. Response to environmental temperatures in Brahman calves during the first compared to the second day after birth. Journal of Animal Science, v.69, n.11, p.4419-4427, 1991.

TOLEDO, L.M. Relações materno-filiais em bovinos de corte nas primeiras horas após o parto: efeitos ambientais. Pirassununga: Faculdade de Zootecnia e Engenharia de Alimentos, 2001. 62p. Dissertação (Mestrado em Zootecnia) Faculdade de Zootecnia e Engenharia de Alimentos, 2001.

YOUSEF, M.K.; KIBLER, H.H.; JOHNSON, H.D. Thyroid activity and heat production in cattle following sudden ambient temperature changes. Journal of Animal Science, v.26, n.1, p.142-148, 1967. 